from the thin purulent material becoming sucked down the bronchi of the other lung. This was also a very alarming condition during eac

On October 29th I reopened his chest, but enteriorly, for his moist sounds and bronchophony were best heard at gbout the interval between the fourth and fifth ribs on the right side, very near the nipple. On this occssion I succeeded in introducing the aspirating needle into the pulmonary cavity. This opening I enlarged with Lister's long sinus forceps, but, owing to the retraction of the lang, I was unable to drain it as I pleuron in the direction of the cavity in the lung, and the air allowed to enter with each inspiration, for it was argned that by causing collapse of the lung the pulmonic cavity would be considerably decreased in size, whilst adhesions would oocur between the lung and the anterior parietes. No marked benefit followed this operation, and the amount of expectoration was not materially lessened or otherwise altered, whilst the range of temperature was from $99^{\circ}$ to $102^{\circ}$.

On November 19th the wonnd was opened up, a rib excised interiorly to the extent of 1 in., and a determined effort made to drain the bronohiectasis; $a$ tube was introduced into it, but the movements of the chest walls in respiration prevented it from staying there. Highly offensive matter flowed from this wound in a day or two, and a corresponding decresse was expectorated, and the boy's condition improved; the tempersture became normal, and the drainage tube was left out on the tenth day. Gradually he gained weight and all expectoration cessed.

On December 2nd the right side of the chest was exposed to the action of $x$ rays, which was repested twice s week-four exposures in all. He then left the hospitil to spend some weeks.at Torquay, air at that time entering both lungs freely, pleural friotion sounds being beard at the lower portion of the right lung, both back and front, whilst he had gained 1 st. in weight.

This case presented one or two special points of interest. Thus there were no adhesions found strong enough to prevent the lung from retracting from the wound. Neither was there anything to guide the palpating finger to the dilated bronchus.

Again, the movements of respiration, so much exaggerated anteriorly as compared to the movements of the ribs posteriorly, repeatedly pulled out the tube from the bronchipctasie, for although the latter was carefully mapped out prior to operating, as soon as air entered the plearon the bronchiectasis' was drawn upwards and towards the mediastinum.

The operation was therefore divided into three stages. On the efficient drainage of the bronchiectasis being established, the temperature fell to normal, and remained so with cessation of all swestings.

Lastly, the collapsed lung and injured pleural cavity were subjected to $x$ says for twenty minutes on four occasions.

Probably this case could not have been tuberculous, or the lung and sinus tracks would not have healed so well; but the quick ending of the case and restoration of the lung for breathing purposes was in my estimation materially helped by this procedure.

\section{THE USE OF SCOPOLAMINE-MORPHINE IN LABOUR.}

By DUDLEY CORBETT, M.A., M.B., B.Ch.Oxon, LATE HOUSE-PHYSIOIAN, GENERAL LYING-IN HOSPITAL, YORE ROAD,

IN view of the interest that is now being taken in scopolamine, I have thought that my experience with this drug may be of value. Its power to produce analgesia in labour is now generally known, but unfortunately in many cases this result is only obtained with the risk that the child will be born in a state of apnoea. The following results will, I hope, suggest how this danger may be avoided.

\section{Dosage.}

The compouna tabloids of Messrs. Burroughs Wellcome were employed; these are in two strengths-" $A$," scopolamine I 10 grain, morphine $\frac{1}{6}$ grain, and atropine $1 \frac{1}{8} \sigma$ grain; "B," scopolamine $1 \frac{1}{6} \sigma$ grain, morphine $\frac{1}{4}$ grain, and atropine $x_{5}^{1} \sigma$ grain. In all cases the drug was administered subcutaneously.

\section{Analgesic Effect.}

Of 20 cases, 4 exhibited complete analgesia, none of them remembering anjthing of the birth of the child.
Three of these had one dose of " B" only, and the fourth had one dose of "A " followed two and a half hours later by one of "B"; in this case forceps were empjojed for delivery without chloroform. The patient was neaware that anything of the kind had been done.

In 13 there was a marked effect, the patients sleeping between the pains which caused little suffering. In 3 the effect was slight or absent.

\section{Influence on Uterine Contractions.}

In 4 cases in which inertia apparently followed the in. jection it is probable that primary inertia had been present throughout, masked by the distress of the patient. Where delay occarred daring the second stage, it was olear that this was due to the absence of voluntary effort.

\section{The Effect on the Fetus.}

My cakes seem to show that where delivery occurred at four hours or less after the injection the child was invariably affected to a greater or less degree. The only exceptions to this were 2 cases in which the drug was without any $\mathrm{fffect}$ upon the mother whatever.

Of the 20 cases described above, only 18 can be counted so far as the effect on the child is concerned, because one of them was a case of twins and in another the infant was premature. Of these 18, in 9 the child was born perfectly normal ; in these delivery occurred $13 \frac{1}{2}, 9,7 \frac{1}{2}, 7,6,5 \frac{1}{2}$ and $4 \frac{1}{2}$ hours respectively after the injection. In the 2 cases already mentioned delivery occurred one and three-quarter hours and half an hour after an injection which was without any effect on the mothers.

In 7 cases the child was born sleepy and slightly cyanosed. They all responded to gentle stimulation, and never gave any anxiety as to their rapid recovery. Delivery oocurred $3,2 \frac{4}{4}, 4,1 \frac{1}{4}, 2,4$, and $1 \frac{1}{4}$ hours respectively from the time of the injection. All the mothers received one dose of "B " only, except the last, who had a second injection of "A."

In 2 cases the child was badly asphyxiated. In the first the mother received two injections, the first of " B" and the second of "A," and the child was delivered with forceps three and three-quarter hours from the second injection. It was not breathing, was cyanosed, and the heart was beating very slowly. A hot bath was given and artificial respiration employed, with the result that recovery ensued in twenty minutes.

The second case was one marked by an extremely tedious and distressing first stage, and shows the value as well as the dangers of scopolamine.

The patient was a primipara, aged 23. Labour started on April 22nd, and the pains were so severe as to prevent her sleeping the same night. On April 23rd distressing pains continued, rendering her hyoterical. In the evening, when examined, the os barely admitted the finger, and the abdomen was extremely distended, looking like a osse of hydramnios. whe was admitted the same night. In the morning of April 24th she had an injection of " $B$," and slept for five April 24th she had an injection of "B," and slept for five the os only admitted two fingers, and so, other methods of pacifying her failing, she received another injection of " $B$ " with good result. At midnight the membranes were ruptared artiflcially, as it seemed likely that there was an excess of liquor: this, however, was not the case. At 2 a.m. on April 25th she again became assailed by violent and distressing pains, and became very noisy. As the os was not yet three parts dilated she received another injection of "B," with the result that she slept until 5.15 a.m., hardly noticing the pains, and was almost nnconscious of delivery at 5.45 a.m., three and three-quarter hours from the last injection, and about seventytwo hours from the onset of labour. The child was large, and weighed nearly 10lb., thus accounting for the size of the abdomen. It was badly ssphyxisted, being cysnosed and making no endeavour to breathe. It was put into a hot bath, brandy and endeavour to breathe. It was put into a hot bath, brandy and
ether injections given. and artiflcial respiration was kept up for forty-five minutes. Fortunately recovery was then rapid, and the child did extremely well later.

Thinking that the morphine was mainly responsible for these cases of asphyxia, I tried combining strychnine with the mixture, $\frac{1}{2}$ grain with the "B" injection and $\frac{1}{58}$ grain with the "A"; these doses for the sake of brevity I will call "BS" and "AS." The strychnine did not seem to mitigate the good results on the mother. In one case there was bat little effect, but in the rest the result was good. Three of the patients had complete analgesia ; the others were distinctly relieved. 
Of 10 cases, 9 were normal children, delivery occurring $30,13,12,8,4 \frac{3}{4}, 4,2 \frac{3}{4}, 2 \frac{1}{2}$ hours rel puctively after the injec. tions. The first 6 cases are of no value as far as these results are concerned; but the last 3 are suggestive in view of the results in the first series, for in each case the mother received relief, and the child was born within four hours from the injection. In these 3 the dose was "BS" for the first two and "AS" for the last. The remaining case, however, shows that one cannot rely upon similar results in all cases. The child was born three hours after an injection of "BS"; it was drowsy and respiration intermittent, but recovered in twenty minutes after a hot bath.

In a recent paper Drs. Freeland and Solomons showed 1 that in their 100 cases, where morphine was, as a rule, never given in greater doses than $\frac{1}{6}$ grain, there was only one case of apnoea, and in this t grain was given. It is probable, then, that the cases of apnoes in my series were to a certain extent due to the larger doses of morphine usually smployed. The above authors conclude that the dangers to the fetus bave been much exaggerated; whether this is so or not it is elear that, in view of some of the preparations and combinations of scopolamine at present on the market, caution should be employed in their use.

\section{Conclusions.}

My conclusions are as follows:

1. The scopolamine-morphine combination is of great value where hysteria and distress are manifest during the first stage of labour. If possible it should only be given in the first stage and not repeated.

2. No ill effects to the mother need be expected even with full and repeated doses.

3. No ill effects need be expected for the child, even where the mother has had full and repeated doses, provided that delivery does not take place at four hours or less from the time of the last dose, otherwise apnoes will ensue. On the other hand, where the drug is without effect on the mother it is not likely to affect the child, even if born within four hours.

4. The cause of the apnoes is probably the morphine, and so where it is necessary to give the drug late in the first stage, or early in the second, the morphine should not be given in larger doses than $\frac{1}{8}$ grain, or. omilted.

5. A hot bath is the best treatment for the apnoea.

6. Strychnine may prove to be a useful addition to the mixtare. It does not diminish the analgesic effect of the combined dreg, and it may help to prevent the apnoea in the child.

My best thanks are due to Dr. J. S. Fairbairn, physician to the hospital, for his kind suggestions and permission to pablish these results.

Reference.
1 British Medical Journat, January 28th, 1911.

\section{EVIDENCE OF RECENT SEVERE ILLNESS AFFORDED BY THE NAILS. \\ Bx NORMAN FLOWER, M.A., M.B.OxoN., With a Note by \\ Sir SAMUEL WILKS, BT., F.R.S.}

I BELIEve that attention was first drawn to this somewhat curious condition of the nails by Sir Samuel Wilks in a communication to the Lancet of January 2nd, 1869, since when a number of cases have been reported from time to time. The following case illustrates the condition so clearly that it is perhaps worth recording.

The patient was a lady, aged 61, who was seen for the first time on June 11th, the third day of her illness, due to a locelizing appendicitis. Owing to the stoutness of the patient abdominal examination was rendered very difficult.

On June 18th temperature rose to $101.8^{\circ}$, and pulse 106. Examination under an ansesthetio revealed an ill-defined Examination under an anaesthetio revealed an ill-defined proceeded with, and after opening the abscess I inserted a large tabe. Drainage was good, and all went apparently well until June 21st, when secondary haemorrhage commenced. All the stitches were removed, and both fat and muscle of the abdominal wall were found to be gangrenous. No large bleeding points were found, bat oozing was general.

On the following day, June 22nd, the patient became janndiced cid semi-comatose, so that we feared the onset of suppurative pylephlebitis. There was incontinence of both urine and faeces. Subcutaneons and intravenous infusion was resorted to, with but little improvement. Rectal salines were not retained.

On June 23rd the patient was quite comatose, the pulse imperceptible, conjunctivae shrivelled. Death was hourly expected. Saline infasion, etc., was continued.

On June 25th there was slight. improvement, incontinence ceased, and the jaundice commenced to recede.

On July 3 rd there was retention of urine, and the catheter was used.

On July 8th there was no attempt at repair in the wound; the lack of vitality and the toxic condition of the patient was wel shown by the fact that the minute incision made for the intravenous infusion took five weeks to heal.

On July 13th the patient developed hypostatio pneumonia, from which a good recovery was made.

Although all the usual precautions were taken at the time of the saline infusion, the patient developed a pectoral abscess on the right side, no sign of suppuration appearing until four weeks afterwards (July 31st). A week later the same condition appeared on the left side.

The abdominal wound now commenced to granulate, eventually leaving a very small cicatrix. On August 24th the patient got up for the first time, and it was noticed that upon asl fise nails of both fingers and toes were transverse whive iines, ciethird of the way ap In addition to these marks there were transverse ridges, but these were only marked upon the index transverse ridges, but these were only marked npon the index
and third fingers of the right hand. The nail on the proximal

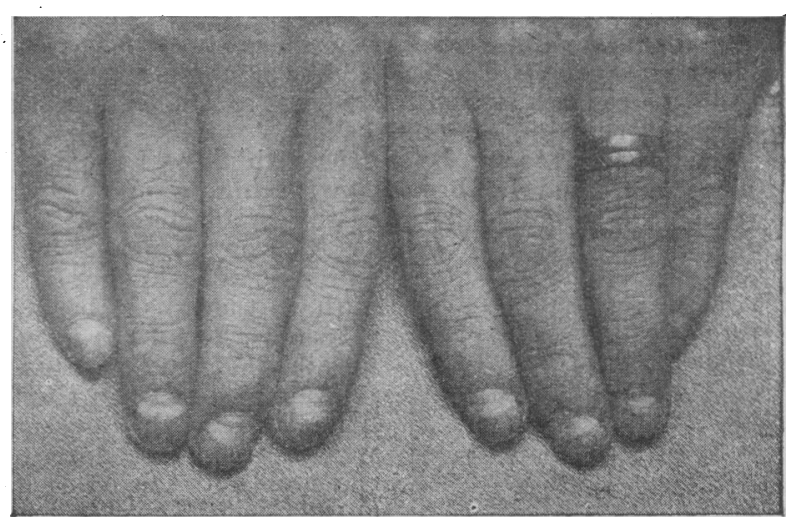

Fig. 1.

side of the lines was of a much softer nature. Allowing six side of the lins was of a much solter nsture. Allowing six months as an average for the nails to grow ont, the position of
the liness exactly corresponded to the roots of the nails. When the patient was in the apparently moribund state two months before.

On September 10th the patient was walking without aid.

I am indebted to Sir Samuel Wilks, to whom the photograph was submitted, for his kindness in permitting me to quote the following comments and oases :

"I am much obliged to you for your interesting case and the photo of the hands of the patient, which is by far the best representation of the markings on the nails which I have seen, showing, no doubt, the time of the illness which you describe.

"The case is quite in accordance, as regards its history, with all the other cases which I have seen-that is, the condition of the patient at the time when these white marks took place. When I first noticed them, I was under the impression that they were indicative of some previous severe illness, but I subsequently learnt that this was not the case, for, if true, they would be of every. day occurrence, and well known to every medical man, and certainly not requiring the special notice which I believe I was the first to make.

"There may, however, be lesser degrees of these conditions where the lines might be less marked, and so perhaps overlooked.

"My opinion is that the furrow and white line on the nails show the line of death or approaching death which takes place during the patient's illness. In all the cases I have seen or known where these marks have appeared the patient has been at death's door; ho has been regarded by the medical man and friends as dangerously ill, and, indeed, in the jaws of death, unless be soon rallied and then recovered. He has always become cold, palseless, and death written on his face, causing the greatest anxiety to his friends, and in this state he may continue for some honrs or several days. If he should fortanately recover, the sign of death is written upon him. Daring this precarious period all fanctionizing is 